This item was submitted to Loughborough's Research Repository by the author.

Items in Figshare are protected by copyright, with all rights reserved, unless otherwise indicated.

\title{
Enhanced water barrier properties of surfactant-free polymer films obtained by macroRAFT-mediated emulsion polymerization
}

PLEASE CITE THE PUBLISHED VERSION

https://doi.org/10.1021/acsami.8b01040

\section{PUBLISHER}

(C) American Chemical Society.

\section{VERSION}

AM (Accepted Manuscript)

\section{PUBLISHER STATEMENT}

This work is made available according to the conditions of the Creative Commons Attribution-NonCommercialNoDerivatives 4.0 International (CC BY-NC-ND 4.0) licence. Full details of this licence are available at: https://creativecommons.org/licenses/by-nc-nd/4.0/

\section{LICENCE}

CC BY-NC-ND 4.0

\section{REPOSITORY RECORD}

Martin-Fabiani, Ignacio, Jennifer Lesage de la Haye, Malin Schulz, Yang Liu, Michelle Lee, Brendan Duffy, Franck D'Agosto, Muriel Lansalot, and Joseph L. Keddie. 2018. "Enhanced Water Barrier Properties of Surfactant-free Polymer Films Obtained by Macroraft-mediated Emulsion Polymerization". Loughborough University. https://hdl.handle.net/2134/32831. 


\section{Enhanced Water Barrier Properties of Surfactant-}

\section{Free Polymer Films Obtained by MacroRAFT-}

\section{Mediated Emulsion Polymerization}

Ignacio Martín-Fabiani, ${ }^{1,}$ * Jennifer Lesage de la Haye, ${ }^{2}$ Malin Schulz, ${ }^{3}$ Yang Liu, ${ }^{3,4}$ Michelle Lee, ${ }^{5}$

Brendan Duffy, ${ }^{5}$ Franck D’Agosto, ${ }^{2}$ Muriel Lansalot ${ }^{2}$ and Joseph L. Keddie ${ }^{3}$

${ }^{1}$ Department of Materials, Loughborough University, Loughborough LE11 3TU, Leicestershire, United Kingdom

${ }^{2}$ Univ Lyon, Université Claude Bernard Lyon 1, CPE Lyon, CNRS, UMR 5265, Chemistry, Catalysis, Polymers and Processes (C2P2), 43 Bd du 11 Novembre 1918, 69616 Villeurbanne,

France

${ }^{3}$ Department of Physics, University of Surrey, Guildford GU2 7XH, United Kingdom

${ }^{4}$ Department of Chemistry, University of Toronto, 80 St. George St., Toronto ON, M5S 3H6, Canada

${ }^{5}$ CREST, FOCAS Research Institute, Dublin Institute of Technology, Kevin Street, Dublin 8, Republic of Ireland

Key words: surfactant-free; waterborne; macroRAFT; adsorption isotherm; latex; coatings 


\section{ABSTRACT}

The presence of low molar mass surfactants in latex films results in detrimental effects on their water permeability, gloss and adhesion. For applications as coatings, there is a need to develop formulations that do not contain surfactants and that have better water barrier properties. Having previously reported the synthesis of surfactant-free latex particles in water using low amounts (< $2 \mathrm{wt} \%$ ) of controlled radical polymer chains (Lesage de la Haye et al. Macromolecules 2017, 50, 9315-9328), here we study the water barrier properties of films made from these particles and their application in anti-corrosion coatings. When films cast from aqueous dispersions of acrylate copolymer particles stabilized with poly(sodium 4-styrenesulfonate) (PSSNa) were immersed in water for three days, they sorbed only 4 wt.\% water. This uptake is only slightly higher than the value predicted for the pure copolymer, indicating that the negative effects of any particle boundaries and hydrophilic stabilizing molecules are minimal. This sorption of liquid water is five times lower than what is found in films cast from particles stabilized with the same proportion of poly(methacrylic acid) (PMAA), which is more hydrophilic than PSSNa. In water vapor with 90\% relative humidity, the PSSNa-based film had an equilibrium sorption of only 4 wt.\%. A small increase in the PMAA content has a strong and negative impact on the barrier properties. Nuclear magnetic resonance relaxometry on polymer films after immersion in water shows that water clusters have the smallest size in the films containing PSSNa. Furthermore, these films retain their optical clarity during immersion in liquid water for up to 90 minutes, whereas all other compositions quickly develop opacity ("water whitening”) as a result of light scattering from sorbed water. This implies a remarkably complete coalescence and a very small density of defects, which yields properties matching those of some solvent borne films. The latex stabilized with PSSNa is implemented as the binder in a paint formulation for application as an anti-corrosive 
barrier coating on steel substrates and evaluated in accelerated weathering and corrosion tests. Our results demonstrate the potential of self-stabilized latex particles for the development of different applications, such as waterborne protective coatings and pressure-sensitive adhesives.

\section{INTRODUCTION}

Waterborne polymer colloids, also known as latex, are the primary component of numerous products such as paints, ${ }^{1}$ coatings, ${ }^{2}$ adhesives, ${ }^{3}$ inks, ${ }^{4}$ agrochemical formulations, ${ }^{5}$ pharmaceutical coatings, etc. The conventional method used for their synthesis is emulsion polymerization in the presence of surfactants. The use of these low molar mass substances leads to deleterious effects in several film properties. Surfactants are not chemically bonded, but physically adsorbed to the surface of the latex particle. Because of the complex interplay between the evaporation of water, the diffusion of surfactants and colloidal particles, and the desorption and adsorption of surfactant on particles, ${ }^{6}$ a non-uniform distribution of surfactant throughout the dried film thickness develops during film formation. As is shown in Figure 1a, surfactants can accumulate at the top ${ }^{7}$ and/or the bottom ${ }^{6,8}$ of the dry film. An excess of surfactant at the top surface has proven to reduce the gloss of the final film and increase its tackiness. ${ }^{9}$ An uneven distribution affects adhesion properties, as surfactants are at the locus of failure in peeling tests, ${ }^{10}$ and the peel strength varies significantly depending on the surfactant type and concentration. ${ }^{11,12}$

The presence of surfactants has been found to have a negative impact on polymers' barrier properties when exposed to liquid water or vapor. The diffusion coefficient of water and its solubility in polymers are both higher in polymers containing surfactants. ${ }^{13}$ Butler et al. found a strong dependence of the water sensitivity of latex films on the type of surfactant used. ${ }^{14}$ They reported that latex films absorbed up to $100 \%$ of their mass in water after immersion in liquid water for only $100 \mathrm{~min}$., depending on the choice of surfactant. A related problem in conventional 
latex coatings is their tendency to develop opacity (i.e. to whiten) upon exposure to liquid water or vapor. This so-called "water whitening” phenomenon is explained by light scattering from water clusters that have a refractive index that is different from the polymer. ${ }^{15,16}$ Water reservoirs swell upon continuous exposure to water, thus generating holes in a film that can lead to failure. ${ }^{17}$ Surfactants are known to be exuded by latex films in which they are not miscible, after which they can be rinsed away and released into the environment, leading to pollution. ${ }^{18}$ The poor barrier properties of conventional latex films make them poor candidates for binders in protective and anti-corrosion coatings.

To investigate water uptake in polymers in depth, several complementary techniques need to be used. Differential scanning calorimetry of samples after immersion in water enables the determination of the amount of mobile and freezable water, ${ }^{19}$ and also the amount of dissolved and non-freezable water by the shift of the glass transition temperature towards lower values (i.e. plasticization by water). ${ }^{20} \mathrm{NMR}$ relaxometry has been used recently to gain further information on the water distribution within the film. Three regions have been identified in films that were immersed in water, attributed to molecularly dissolved water (and mobile polymer), to bound interfacial water, and to mobile water in pockets. ${ }^{17}$ 
(a)

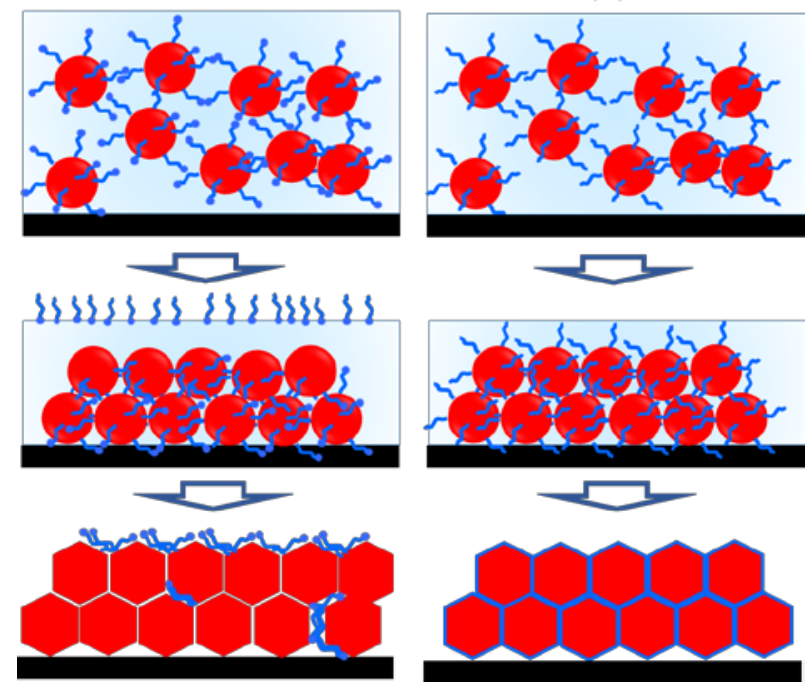

Figure 1. Sketches depicting the film formation process of polymer particle dispersions synthesized using emulsion polymerization performed in the presence of: (a) a low molar mass surfactant and (b) a low concentration of hydrophilic controlled radical chains (typically $\leq 2 \mathrm{wt} . \%$ )

Over the years, different strategies have been developed to synthesize surfactant-free latexes and thus overcome the various problems and limitations of conventional emulsion polymer films. Several studies have explored the use of (reactive) macromolecules as particle stabilizers instead of low molar mass surfactants. These approaches result in stabilizers that are strongly anchored to the particle surface. Successful latex syntheses have been reported, but the developed strategies can sometimes require high amounts of hydrophilic species, and the efficiency of stabilizer anchoring can be relatively poor. ${ }^{21-23}$ One very recent and particularly efficient approach takes advantage of the chain-end reactivity of hydrophilic macromolecules obtained by reversibledeactivation radical polymerization (RDRP) for the polymerization of hydrophobic monomers. This strategy, coined polymerization-induced self-assembly (PISA), notably makes use of reversible addition-fragmentation chain transfer (RAFT), one of the most versatile RDRP 
processes, to mediate emulsion polymerization by hydrophilic polymer chains (also called macroRAFT), ${ }^{24,25}$ acting as a stabilizer precursor. ${ }^{26-29}$ In contrast to the adsorbed surfactants, these hydrophilic macromolecules are covalently bonded to the particle surface. As depicted in Figure 1b, during film formation stabilizers remain anchored to the particle surface and form a honeycomb structure throughout the film. ${ }^{30}$ This structure has likewise been reported in films made from inorganic/polymer nanocomposite particles, in which the cellular walls are composed of a percolating inorganic phase. Such hydrophilic honeycomb structure, as it is percolating from the surface to the bottom of the film, results in a fast initial water uptake. However, it reaches a saturation plateau where the water content in the film remains constant. ${ }^{31-33}$ In films containing surfactants, water uptake does not reach a plateau and water reservoirs continuously swell. ${ }^{34}$

Although the use of PISA solves the problem of surfactant mobility and aggregation through self-stabilized particles, the amount of hydrophilic species used in previous work (> 5 wt.\%) is still too high to ensure good water barrier properties. Recent studies have been able to reduce this figure to below 3 wt.\% while keeping particles stable using poly(acrylic acid) (PAA), ${ }^{30,35}$ poly(methacrylic acid) (PMAA), ${ }^{36,23}$ or poly(sodium 4-styrenesulfonate) (PSSNa). ${ }^{36}$ However, not enough work has yet been devoted to investigating the water barrier properties of films made from macroRAFT-stabilized latexes. Gonzalez et al. reported an increase in the water uptake of latex films stabilized with macroRAFT chains with an increasing length. ${ }^{35}$ Velasquez et al. synthesized a PSSNa-stabilized latex that did not water whiten after immersion in water for $2 \mathrm{~h}$ at $95{ }^{\circ} \mathrm{C} .{ }^{36}$ With the specific effects of macroRAFT chemical composition and concentration on the water barrier properties of latex films being unreported, there is a critical need to evaluate this new type of material to pave the way for applications. 
Here, we have synthesized latex particles stabilized by two macroRAFT agents with different chemical compositions, based on either PMAA or PSSNa. We present a thorough study of the water sorption properties of their films in comparison to films of the same monomer composition obtained from surfactant-free latexes stabilized by surface charges coming from monomer units. Our research advances the understanding of the influence of the macroRAFT hydrophilicity and its concentration on the water sorption with the aim of obtaining a formulation with a greater barrier resistance. Thereafter, we use the insight from our fundamental study to inform the development of an application of the material: a pigmented barrier coating on steel to prevent corrosion.

EXPERIMENTAL

Materials. $n$-Butyl acrylate (BA, Acros Organics, 99\%), methyl methacrylate (MMA, Acros Organics, 99\%), methacrylic acid (MAA, Acros Organics, 99.5\%), sodium 4-styrenesulfonate (SSNa, Aldrich, > 99.5\%) and ammonium persulfate (APS, Acros Organics, 98\%) were used as received. Water was deionized before use (Purelab Classic UV, ElgaLab Water).

Procedure for the emulsion copolymerizations of BA and MMA mediated by hydrophilic PMAA or PSSNa macroRAFT agent (PMAA-1, PMAA-1.5 and PSSNa-1).

The macroRAFT agent (either PMAA or PSSNa) was synthesized as described in the literature. ${ }^{36,37}$ The aqueous macroRAFT agent solution was used in the following without further purification. The emulsion polymerizations mediated by hydrophilic PMAA or PSSNa macroRAFT agent followed the same procedure. They were performed at $70{ }^{\circ} \mathrm{C}$ in a $250 \mathrm{~mL}$ or a $500 \mathrm{~mL}$ reactor equipped with a condenser and an anchor-blade stirrer. In a typical experiment (PSSNa-1, Table 1), APS (81.3 mg, $3.56 \times 10^{-4} \mathrm{~mol}$ ) was added to a solution of previously synthesized PSSNa 
macroRAFT agent (12.4 wt\% aqueous solution, $1.0 \mathrm{wt} \%$ of PSSNa based on monomer, bom). Water content was adjusted so that the solids content of the final latex $\tau$ was $\sim 40 \mathrm{wt} \%$ (with $\tau=\left(\mathrm{m}_{0}\right.$ $\left.(\mathrm{BA})+\mathrm{m}_{0}(\mathrm{MMA})\right) / \mathrm{m}_{0}$ (latex)). The $\mathrm{pH}$ of this solution was adjusted to 7 with $1 \mathrm{~mol} \mathrm{~L}^{-1}$ and $0.1 \mathrm{~mol} \mathrm{~L}{ }^{-1} \mathrm{NaOH}$ aqueous solutions. BA (72.0 g, $\left.5.62 \times 10^{-1} \mathrm{~mol}, 60 \mathrm{wt} \% \mathrm{bom}\right)$ and MMA (48.0 g, $4.79 \times 10^{-1} \mathrm{~mol}$, $40 \mathrm{wt} \%$ bom) were added and the resulting mixture was degassed for $30 \mathrm{~min}$ under nitrogen. The polymerization was stopped after $6.5 \mathrm{~h}$ of stirring and a conversion of $95 \%$ was determined by gravimetry. The final latex was thus stirred under nitrogen bubbling at $60{ }^{\circ} \mathrm{C}$ during a period of $6 \mathrm{~h}$ to evaporate the remaining monomer. The emulsion polymerizations PMAA1 and PMAA-1.5 were stopped after $5 \mathrm{~h}$ and $4 \mathrm{~h}$, respectively (Table 1). They both reached $100 \%$ conversion.

\section{Procedure for the conventional emulsion copolymerizations of BA and MMA in the presence of methacrylic acid (MAA-1 and MAA-1.5).}

The syntheses of MAA-1 and MAA-1.5 followed the same procedure. They were performed at 70 ${ }^{\circ} \mathrm{C}$ in a $250 \mathrm{~mL}$ reactor equipped with a condenser and an anchor-blade stirrer. In a typical experiment (MAA-1), APS (271.5 mg, $\left.1.19 \times 10^{-3} \mathrm{~mol}\right)$ and MAA (339.7 mg, $3.93 \times 10^{-3} \mathrm{~mol}$ ) were diluted in water (55.4 g). The $\mathrm{pH}$ of this aqueous solution was adjusted to 7 with a $1 \mathrm{~mol} \mathrm{~L}^{-1}$ $\mathrm{NaOH}$ aqueous solution. BA (24.0 g, $1.87 \times 10^{-1} \mathrm{~mol}$, $\left.60 \mathrm{wt} \% \mathrm{bom}\right)$ and MMA (16.0 g, $\left.1.60 \times 10^{-1} \mathrm{~mol}, 40 \mathrm{wt} \% \mathrm{bom}\right)$ were added and the resulting mixture was degassed for $30 \mathrm{~min}$ under nitrogen. The polymerization was stopped after $5 \mathrm{~h}$ of stirring and a conversion of $100 \%$ was determined by gravimetry. The exact same procedure was followed for MAA-1.5 using 513.5 mg of MAA $\left(5.93 \times 10^{-3} \mathrm{~mol}\right)$. After $5 \mathrm{~h}$, a final conversion of $100 \%$ was also obtained. 
Table 1. Emulsion copolymerizations of BA and MMA mediated by hydrophilic PMAA (PMAA-1, PMAA-1.5) or PSSNa (PSSNa-1) macroRAFT agents, or in the presence of MAA (MAA-1, MAA-1.5)

\begin{tabular}{|c|c|c|c|c|c|c|c|c|}
\hline Sample & $\begin{array}{l}\text { Monomer }^{a} \text { (wt } \\
\text { fraction) }\end{array}$ & $\begin{array}{c}\text { Macro } \\
\text { RAFT } \\
\text { agent } \\
\text { (conc.) }\end{array}$ & $\begin{array}{c}M_{\mathrm{n}, \exp } \\
\text { macro } \\
\text { RAFT } \\
\left(\mathrm{g} \mathrm{mol}^{-1}\right) \\
/ \oplus\end{array}$ & $\begin{array}{l}\text { Conv } \\
{ }^{d}(\%)\end{array}$ & $\begin{array}{l}\text { Time } \\
\text { (h) }\end{array}$ & $\begin{array}{c}\tau^{f} \\
(\mathrm{wt} \%)\end{array}$ & $\begin{array}{c}D_{\mathrm{z}} \\
(\mathrm{nm}) / \\
\mathrm{PDI}^{g}\end{array}$ & $\begin{array}{l}T_{\mathrm{g}}{ }^{h} \\
\left({ }^{\circ} \mathrm{C}\right)\end{array}$ \\
\hline PMAA-1 & $\begin{array}{c}\text { BA/MMA } \\
(60 / 40)\end{array}$ & $\begin{array}{l}\text { PMAA } \\
(1 \mathrm{wt} \%)\end{array}$ & $\begin{array}{l}2290 / \\
1.13^{b}\end{array}$ & 100 & 5.0 & 40.3 & $\begin{array}{l}196 / \\
0.02\end{array}$ & $-26.4,+17.9$ \\
\hline PMAA-1.5 & $\begin{array}{c}\text { BA/MMA } \\
(60 / 40)\end{array}$ & $\begin{array}{c}\text { PMAA } \\
(1.5 \\
\text { wt\%) }\end{array}$ & $\begin{array}{l}2290 / \\
1.13^{b}\end{array}$ & 100 & 4.0 & 40.6 & $\begin{array}{l}149 / \\
0.02\end{array}$ & $-23.6,+13.9$ \\
\hline MAA-1 & $\begin{array}{c}\text { BA/MMA/MAA } \\
(59.5 / 39.7 / 0.8)\end{array}$ & None & - & 100 & 5.0 & 40.0 & $\begin{array}{l}1158 / \\
0.11^{*}\end{array}$ & $-25.8,+16.2$ \\
\hline MAA-1.5 & $\begin{array}{c}\text { BA/MMA/MAA } \\
(59.2 / 39.5 / 1.3)\end{array}$ & None & - & 100 & 5.0 & 40.5 & $\begin{array}{l}630 / \\
0.03\end{array}$ & $-21.2,10.8$ \\
\hline PSSNa-1 & $\begin{array}{l}\text { BA/MMA } \\
(60 / 40)\end{array}$ & $\begin{array}{l}\text { PSSNa } \\
(1 \mathrm{wt} \%)\end{array}$ & $\begin{array}{l}1210 / \\
1.20^{c}\end{array}$ & $99^{e}$ & 6.5 & 40.0 & $\begin{array}{l}192 / \\
0.03\end{array}$ & $-25.2,+14.4$ \\
\hline
\end{tabular}

${ }^{a}$ Monomer proportions are given in brackets, in wt\%. ${ }^{b}$ Number-average molar mass $\left(M_{\mathrm{n}, \exp }\right)$ and dispersity $(\nexists)$ determined by size-exclusion chromatography (SEC) in THF using PMMA calibration. ${ }^{c} M_{\text {nexp }}$ and $Ð$ determined by MALDI-ToF MS analysis. ${ }^{d}$ Conversions were determined by gravimetry. ${ }^{e}$ Conversion determined by ${ }^{1} \mathrm{H}$ NMR. ${ }^{f}$ Solids content $\tau(\%)=\left(\mathrm{m}_{0}(\mathrm{M})+\mathrm{m}_{0}(\right.$ macroRAFT $\left.)\right) / \mathrm{m}_{0}$ (latex). ${ }^{g} D_{\mathrm{z}}$ is the intensity-based harmonic mean particle diameter and PDI the polydispersity index determined by dynamic light scattering before filtration of the final latexes.

${ }^{h} T_{\mathrm{g}}$ is measured at the midpoint, at $20^{\circ} \mathrm{C} \mathrm{min}^{-1}$. Details on the SEC-THF, MALDI-ToF, DLS and DSC characterizations can be found in the Supporting Information. * Particle size is on the edge of the detection range of DLS instrument. 


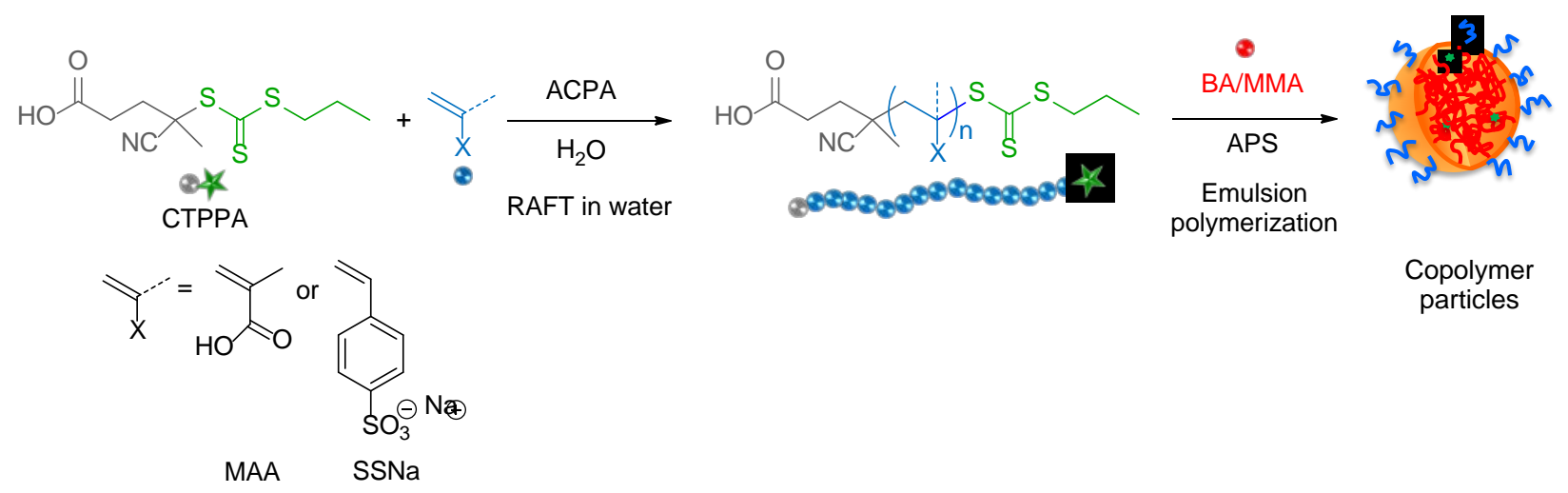

ACPA: 4,4-azobis(4-cyanopentanoic acid)

CTPPA: 4-cyano-4-thiothiopropylsulfanylpentanoic acid

Figure 2. Strategy for the synthesis of the surfactant-free latex particles mediated by hydrophilic PMAA or PSSNa macroRAFT agent.

\section{Characterization}

Information on the techniques used to characterize the latexes and their film properties is provided in the Supporting Information.

Differential scanning calorimetry (DSC). For water sorption experiments, a DSC Q1000 from TA instruments under nitrogen flow $\left(50 \mathrm{~mL} \mathrm{~min}^{-1}\right)$ was used. Samples were prepared by spread-casting a film, approximately $500 \mu \mathrm{m}$ thick, and then drying and film-forming under ambient conditions for 3 days. Then, free-standing films were immersed in deionized water for three days. Finally, they were gently wiped dry with tissue paper and placed in DSC pans. Samples weighed 8-10 mg. A cooling ramp from $25{ }^{\circ} \mathrm{C}$ to $-80{ }^{\circ} \mathrm{C}$ at $10{ }^{\circ} \mathrm{C} \min ^{-1}$ was followed by heating to $90{ }^{\circ} \mathrm{C}$ at $10{ }^{\circ} \mathrm{C}$ $\min ^{-1}$.

Simultaneous DSC/TGA (SDT). The mass loss and heat flow as a function of temperature for water-soaked film samples were recorded simultaneously using a SDT Q600 from TA Instruments. Samples were heated in air up to $150{ }^{\circ} \mathrm{C}$ at $5^{\circ} \mathrm{C} \mathrm{min}^{-1}$. 
Atomic force microscopy (AFM). Samples were prepared by casting $200 \mu \mathrm{L}$ of latex on glass substrates $(18 \mathrm{~mm} \times 18 \mathrm{~mm})$ previously cleaned with acetone and treated inside a UV ozone chamber to remove contaminants (ProCleaner ${ }^{\mathrm{TM}}$, BioForce Nanosciences). Films were formed under ambient conditions for $24 \mathrm{~h}$ prior to imaging. Height and phase images were acquired simultaneously using a NT-MDT Ntegra Prima microscope in intermittent contact mode (using a silicon cantilever with a nominal spring constant of $5 \mathrm{~N} / \mathrm{m}$ ). Images were analysed using the NOVA software.

${ }^{1} H$ NMR of dry and soaked latex films. The Carr-Purcell-Meiboom-Gill (CPMG) pulse sequence was performed using a Kea ${ }^{2}$ nuclear magnetic resonance benchtop spectrometer (Magritek, New Zealand), operating at a frequency of $20 \mathrm{MHz}$. A CPMG pulse sequence: [p90- $\tau$-(p180- $\tau$-echo- $\tau-$ )$\left._{\mathrm{NE}}\right]_{\mathrm{NS}}$ was applied, where p90 and $\mathrm{p}_{180}$ denote an excitation pulse with respectively $90^{\circ}$ and $180^{\circ}$, NE denotes the number of echoes, and NS indicates the number of scans. In this experiment, NE $=500$ echoes ( 32 points per echo with a dwell time of $1 \mu \mathrm{s})$ were logarithmically spaced from 26 $\mu$ s to $2000 \mu \mathrm{s}$. NS was 512 with a repetition time of $1.5 \mathrm{~s}$. The $T_{2}$ relaxation time distributions of fitted curves were obtained using an inverse Laplace transform algorithm developed by Venkataraman et al. ${ }^{38}$ The area under the curves was taken as the total intensity, which was normalized by the original sample mass.

After being immersed in deionized water for 24, 48, 72 and $96 \mathrm{~h}$, the samples were placed in 10 mm NMR tubes sealed with paraffin films to maintain a stable humidity environment. The measurements were performed at a temperature of approximately $30^{\circ} \mathrm{C}$.

UV-visible spectroscopy. A Camspec M350 Double beam spectrophotometer was used to acquire spectra in a wavelength range from 195 to $1100 \mathrm{~nm}$. For the water whitening experiments, glass cover slips ( $22 \mathrm{~mm} \times 22 \mathrm{~mm}$ ) were cut into $9 \mathrm{~mm} \times 22 \mathrm{~mm}$ pieces with a diamond tip pen to enable 
them to fit into cuvettes. Then, $100 \mu \mathrm{L}$ of latex was cast on the slides. The films were allowed to dry for $24 \mathrm{~h}$ under ambient conditions. Then, they were introduced in a cuvette filled with deionized water and optical transmission spectra were measured successively over time.

Water Vapor Sorption. Sorption isotherms were acquired using a benchtop dynamic vapor sorption analyzer (IGAsorp, Hiden Isochema, Warrington, UK). The mass of the sample was measured as a function of time by an ultrasensitive microbalance ( $0.1 \mu \mathrm{g}$ resolution) while the relative humidity was also recorded. Humidity was controlled by using a laminar flow with wet-dry vapor mixing at a constant mass flow rate $\left(500 \mathrm{~mL} \mathrm{~min}^{-1}\right)$ with feedback control. In an adsorption experiment, the sample was initially held at a $\mathrm{RH}$ of $0 \%$ at a temperature of $25{ }^{\circ} \mathrm{C}$ until the mass was stable over time, indicating equilibrium. This mass was used as a reference mass for the mass uptake calculations. The RH was increased to $90 \%$ in steps of $10 \%$. At each RH, the mass was recorded as a function of time until it reached equilibrium, which was designated to be when the mass increase fell below $0.01 \%$ over an interval of $1 \mathrm{~min}$. The water activity, $\alpha_{\mathrm{w}}$, is defined as RH/100. Samples for moisture sorption experiments were prepared by casting the polymer dispersions and solutions onto a poly(tetrafluoroethylene) block with an average wet thickness of $300 \mu \mathrm{m}$. The coatings were then dried at room temperature for a week and then peeled off the substrate. The sample size was $1 \times 1 \mathrm{~cm}$. Specimens were stored in an airtight desiccator with silica gel away from direct sunlight. Before the sample was placed on the hanging pan of the humidity chamber, its thickness was measured using a digital caliper.

\section{RESULTS AND DISCUSSION}


For the purpose of this study, three different surfactant-free latexes have been synthesized to form polymer films free of low molar mass hydrophilic species, and thereafter to evaluate the potential positive impact of using hydrophilic macroRAFT copolymers. The first series of latexes was obtained from macroRAFT-mediated emulsion polymerization using strategies previously reported in the literature, ${ }^{36,23}$ leading to PMAA- or PSSNa-stabilized latex particles (PMAA-1, PMAA-1.5, and PSSNa-1). The first part of the sample name refers to the hydrophilic stabilizing macroRAFT block, and the numerical suffix denotes the concentration (wt.\%). For comparison purposes, a second series of latexes was synthesized in the absence of molecular surfactants, but using the same amount of MAA monomer units as present in the macroRAFT latex, and introducing it as a comonomer during the polymerization (MAA-1 and MAA-1.5) instead of the pre-formed hydrophilic block used in the first series. Here, the name indicates the monomer that was used in the synthesis, and the numerical suffix denotes the concentration (wt.\%). In this second series, the stabilization is only ensured by the negative charges on the sulfate groups coming from the initiator and the deprotonated methacrylic acid units (polymerization performed at $\mathrm{pH}$ 7) available at the surface of the resulting particles. Hence, the MAA-1 and MAA-1.5 latexes are less stable; they are suitable for scientific study but not for applications. The characteristics of all these latexes are displayed in Table 1.

Structural characterization of latex films. After casting and drying, films from each latex were crack-free and transparent. AFM was used to investigate the particle arrangement within the films and to assess the extent of particle coalescence (Figure 3). The latexes synthesized using macroRAFT agents present a much smaller particle size (Figure 3a-b, e), than those synthesized in the presence of MAA (Figure 3c-d). Small particle sizes (less than about $200 \mathrm{~nm}$ ) are usually preferred for applications because of their greater colloidal stability and smaller interparticle void 
size. Increasing the amount of macroRAFT or MAA resulted in a decrease of the latex particle size.

The particles in the PMAA-1 and PSSNa-1 latex films (Figures 3a and e) are randomly packed at the film surface. Judging from this surface structure, the particle packing density is lower than in the films of the hexagonally close-packed MAA particles. Judging from a visual inspection of the images only, it can be concluded that the PMAA-1.5 film (Figure 3b) presents more complete coalescence than the other four latex films. Particle identity is barely apparent in the image. However, clear particle identity is retained at the surface of the other four films shown in Figure 3. The apparently better coalescence observed in the PMAA-1.5 film can be explained by hydroplasticization of the hydrophilic PMAA chains ${ }^{39}$ at the particle surfaces, which are present at a higher concentration than in the PMAA-1 film. In the MAA films, the AA groups are distributed throughout the particle. As particle deformation proceeds during film formation, the average roughness $\left(R_{a}\right)$ value of the films will decrease as the surface flattens. ${ }^{40}$ The value of $R_{a}$, (obtained via AFM analysis) when normalized by the particle size, $D_{z}$, provides a gauge of the particle deformation. This simple analysis (values provided in the Figure 3 caption) shows that the particle deformation of PMAA-1.5, MAA-1, and MAA-1.5 is similar, and the extent deformation is the least in PMAA-1 and PSSNa-1 particles. However, if the main path for water transport in the films is via channels along the particle boundaries and in the Plateau borders at the channel junctions (Figure 3f), then it is relevant to consider their relative sizes in the films.

In relation to barrier properties, for a given volume fraction of space filled, larger particles will have larger channels and radii of Plateau border, $r_{\mathrm{PB}}$. A quantitative analysis is presented in the Supporting Information. The analysis indicates that the PMAA-1.5 film has the lowest value 
of $r_{\mathrm{PB}}$. However, this geometric consideration neglects the effect of the hydrophilicity of the copolymers and the associated water solubility, as will be considered later.

As expected when there is particle deformation, the center-to-center distances of the particles in the AFM images are lower than the DLS particle sizes. However, MAA-1 requires some additional comment. Its center-to-center distance in the AFM analysis (628 $\pm 10 \mathrm{~nm})$ is significantly smaller than the $D_{\mathrm{z}}$ obtained from DLS (Table 1). This discrepancy can be explained by taking into account that the large particle size of MAA-1 is near the DLS detection limit. Therefore, the number-average value of particle size, $D_{n}$, obtained by cryoTEM image analysis (742 nm) was used for the calculations in this particular case.
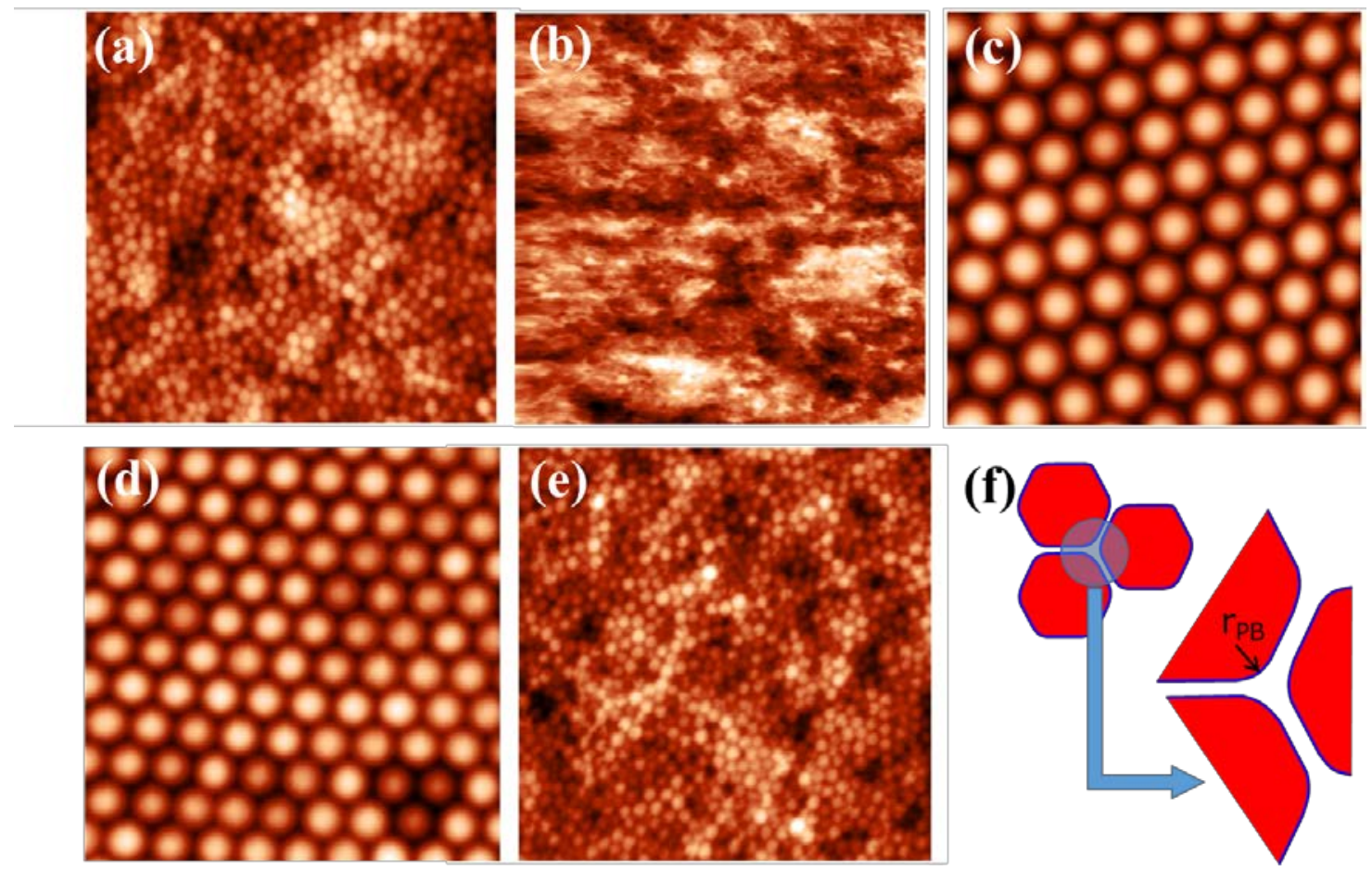

Figure 3. AFM height images $\left(5 \times 5 \mu \mathrm{m}^{2}\right)$ of the surfaces of dried films cast from each of the five latex compositions and their average roughness values normalized by the particle size, $R_{\mathrm{a}} / D_{z}$ : (a) PMAA-1, $R_{\mathrm{a}} / D_{\mathrm{z}}=0.35$; (b) PMAA-1.5, $R_{\mathrm{a}} / D_{\mathrm{z}}=0.04$; (c) MAA-1, $R_{\mathrm{a}} / D_{\mathrm{z}}=0.07$; (d) MAA-1.5, 
$R_{\mathrm{a}} / D_{z}=0.04$; and (e) PSSNa-1, $R_{\mathrm{a}} / D_{z}=0.17$. (f) Sketch showing deformed latex particles and a magnified drawing of a Plateau border.

Liquid water uptake. Films were soaked in deionized water for three days to determine their water barrier properties, which in turn, were expected to be related to the film microstructure. Cooling and heating runs were performed on a DSC instrument to obtain information on the amount and type of water sorbed by the coatings. As shown in Figure 4a, during the cooling run, two different freezing peaks are detected. Each of these two peaks is associated with different water environments. The first and sharper peak lies in the range between $-10{ }^{\circ} \mathrm{C}$ and $-30{ }^{\circ} \mathrm{C}$; it is attributed to mobile water located in water pockets. The second peak, found between $-40{ }^{\circ} \mathrm{C}$ and $50{ }^{\circ} \mathrm{C}$, is associated with more confined water, probably at particle boundaries. ${ }^{15}$ The freezing enthalpies of both types of water, related to the area under the peaks, are presented in Table 2. The subsequent heating run allowed the detection of the ice melting process (Figure $4 \mathrm{~b}$ ). The amount of freezable water within the coating can be calculated by dividing the area under the ice melting peak by the melting enthalpy of ice, taken to be $333.5 \mathrm{~J} \mathrm{~g}^{-1}{ }^{11}$ (Table 2). The latexes containing 1 wt\% macroRAFT sorb the least amount of water among the five materials, and in particular the latex synthesized using PSSNa shows a freezable water uptake of only $2 \mathrm{wt} \%$. In contrast, with the highest amount of PMAA stabilizer, PMAA-1.5 shows a much greater amount of total water uptake (34 wt.\%). This higher level of water uptake suggests that either more or larger pockets of water developed during water immersion, as a result of only a slightly greater amount of hydrophilic component. 


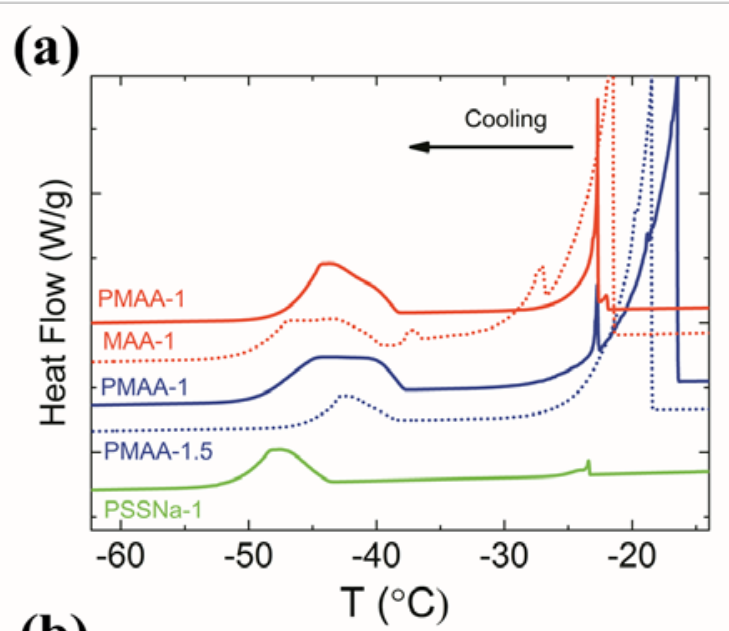

(b)

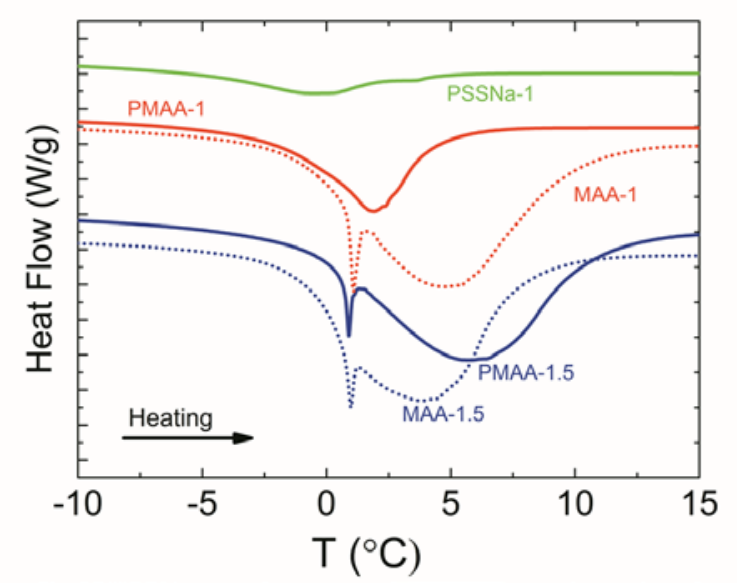

Figure 4. DSC (a) cooling and (b) heating curves of latex films soaked for three days in deionized water.

It is important to note that the DSC analysis only allows the detection of freezable water. There is a non-freezable fraction, related to chemically sorbed water, that can only be detected by shifts in $T_{\mathrm{g}}$ indicating plasticization. ${ }^{20}$ Our polymers present a very broad $T_{\mathrm{g}}$ with a midpoint close to $0{ }^{\circ} \mathrm{C}$ and thus is hidden by the ice melting peak, making it impossible to measure such water using this technique. In order to have a measurement of the total amount of water sorbed by the coatings, a thermogravimetric analysis of the soaked films was carried out (Figure S1). As expected, the total water uptake after $72 \mathrm{~h}$ measured by this technique is similar or larger than that 
measured by DSC, as it also measures the non-freezable water present in the material (Table 2). Again, the latexes with $1 \mathrm{wt} \%$ macroRAFT show the lowest water uptake, with the PSSNa-1 latex film taking up only 4 wt\% water.

To put these results into context, comparison can be made to results in the literature from water immersion studies on similar materials. Gonzalez et al. ${ }^{35}$ synthesized a surfactant-free latex with a similar copolymer compositions of MAA/BA (50/50 wt.\%) to that used here but with a poly(acrylic acid)-based diblock copolymer stabilizer. Their films sorbed approximately 40 wt.\% after immersion for three days in water. In other work, a conventional latex made from a copolymer of styrene and acrylate was found to sorb approximately $10 \mathrm{wt} . \%$ water after only $24 \mathrm{~h}$ of immersion. ${ }^{17}$ For the present experiments, the theoretical water uptake for the pure and homogeneous copolymer can be obtained from the saturated water contents for the homopolymers, which are 2.81 wt.\% for BA and 3.6 wt.\% for MMA. ${ }^{39}$ Therefore, for a 60/40 BA/MMA copolymer, the saturated water uptake is calculated to be $3.1 \mathrm{wt} . \%$. Thus, a value of $4 \mathrm{wt} . \%$ water uptake for the PSSNa-1 films is remarkable, considering that in our films some residual particle boundaries and hydrophilic species (MAA and PSSNa) are present.

Table 2. Thermal data and water uptake of latex films soaked continuously in deionized water for three days

$\begin{array}{ccccc}\text { Sample } & \begin{array}{c}\text { Freezing } \\ \text { enthalpy of } \\ \text { mobile water } \\ \left(\mathrm{J} \mathrm{g}^{-1}\right)^{\mathrm{a}}\end{array} & \begin{array}{c}\text { Freezing } \\ \text { enthalpy of } \\ \text { bound water } \\ \left(\mathrm{J} \mathrm{g}^{-1}\right)^{\mathrm{a}}\end{array} & \begin{array}{c}\text { Freezable water } \\ \text { content }(\mathrm{wt} \%)^{\mathrm{a}}\end{array} & \begin{array}{c}\text { Total water } \\ \text { uptake }(\mathrm{wt} \%)^{\mathrm{b}}\end{array} \\ \text { PMAA-1 } & 10.78 & 5.72 & 7 & 10 \\ \text { PMAA-1.5 } & 10.23 & 35.19 & 17 & 34\end{array}$




$\begin{array}{ccccc}\text { MAA-1 } & 5.37 & 22.64 & 12 & 19 \\ \text { MAA-1.5 } & 4.16 & 39.85 & 17 & 18 \\ \text { PSSNa-1 } & 0.22 & 3.72 & 2 & 4\end{array}$

${ }^{a}$ As determined by differential scanning calorimetry. ${ }^{b}$ As determined by simultaneous differential scanning calorimetry/ thermogravimetric analysis.

NMR relaxometry was carried out to investigate further the degree of confinement of water within the soaked samples. The distribution of the $\mathrm{T}_{2}$ relaxation times of ${ }^{1} \mathrm{H}$ in water is related to the distributions of molecular mobility and hence to the confinement of water to varying extents. Typically for latex films after immersion in water, there are multimodal distributions of $\mathrm{T}_{2}$ times with several peak values. The average $\mathrm{T}_{2}$ value of each peak is a measure of the molecular mobility of the ${ }^{1} \mathrm{H}$-containing molecules, which is inversely related to the extent of the confinement. ${ }^{17}$ Figure 5a shows the $\mathrm{T}_{2}$ distributions for the dry latex films. There is an asymmetric peak with its highest intensity around $0.1 \mathrm{~ms}$. This peak is attributed to the ${ }^{1} \mathrm{H}$ in the mobile groups of the copolymer (most likely the hydrophilic units) and any water dissolved in this polymer phase. The less intense shoulders seen between 0.1 and $1 \mathrm{~ms}$ might correspond to residual water associated with the hydrophilic MAA or SSNa units. After the films are immersed in water for $72 \mathrm{~h}$, a new peak is observed in the $\mathrm{T}_{2}$ region around $100 \mathrm{~ms}$, as shown in Figure $5 \mathrm{~b}$. A higher $\mathrm{T}_{2}$ indicates a lower degree of confinement when compared with the peaks observed in the dry films. It is attributed to water bound or confined at the interfaces between particles. A magnification of this peak for the different latex films is presented in Figure 5c. The area under the peak is proportional to the amount of mobile ${ }^{1} \mathrm{H}$ in the sample and thus to the amount of sorbed water. The smallest area corresponds to the PSSNa film (PSSNa-1), which means that it has the lowest amount of 
confined water. As PSSNa-1 shows the shortest $\mathrm{T}_{2}$ value, the water sorbed by this sample is found within the most confined environment. That is, the water is confined with the smallest clusters in comparison to the other samples.
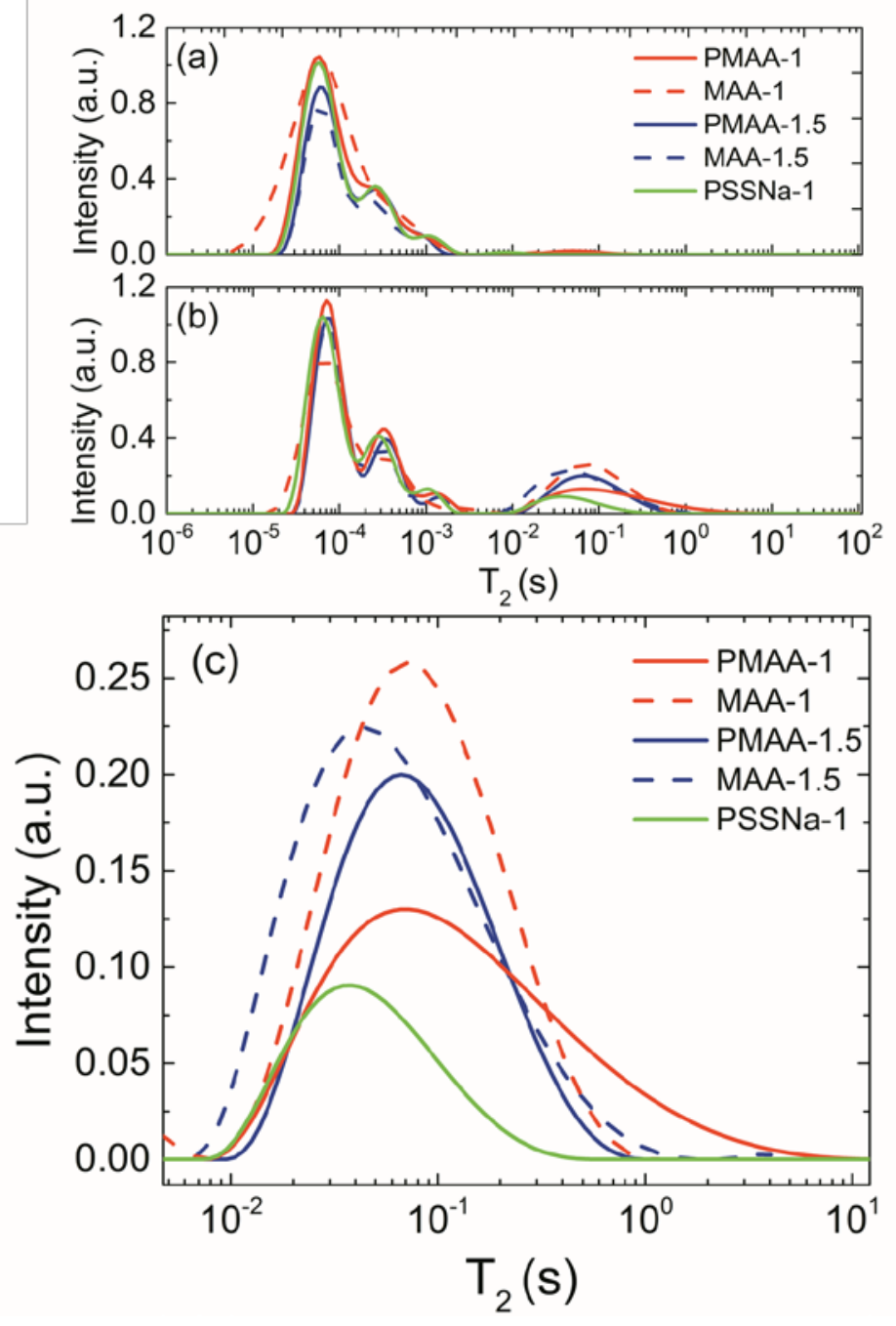

Figure 5. $\mathrm{T}_{2}$ distributions for the various latex films (a) when dry and (b) after soaking in deionized water for 72 h. (c) Enlargement of the mobile component region for the soaked film.

Water whitening in liquid water. It has been shown elsewhere that the loss of optical transmission of latex films when soaked in water is related to both the total amount of water that 
is sorbed and the size of water "pockets" that scatter light. ${ }^{16}$ Thus, an analysis of optical transmission provides indirect information on film structure that complements other measurements. From a practical standpoint, the loss of optical transparency when soaked in water, which is called "water whitening" in the coatings literature, must be avoided for applications in clear coatings.

The optical transmission as a function of variable wavelength, $\lambda$, of incident light is presented in Figure 6 for the different latex films over time of immersion in water. A time of 0 is defined here as being the first scan immediately after adding water to the cuvette. The transparency at this initial time is significantly lower for the films from standard emulsion polymers (see Figure 6c-d), indicating immediate whitening, than for the films containing PMAA or PSSNa macroRAFT stabilizers (see Figure 6a-b, and e). A loss of transparency, especially at shorter wavelengths, is observed to develop with an increasing time of immersion in all samples, with the exception of the PSSNa film. The wavelength dependence is consistent with the expectations from Rayleigh scattering from small "droplets" of water, for which the logarithm of the transmission varies with $\lambda^{-4} .{ }^{16,17}$ Notably, the PSSNa-1 film remains transparent throughout the experiment for times up to $90 \mathrm{~min}$. It has recently been reported ${ }^{13}$ that even solvent-borne polymer films whiten upon water immersion because of small defects (such as voids) due to incomplete coalescence. In waterborne films, these defects are percolating and allow the water to penetrate more rapidly into the coating, resulting in a faster whitening. ${ }^{13}$ The fact that PSSNa-1 films remain transparent in our experiments implies a remarkable coalescence and a very small amount of defects, which matches that of some solvent-borne films. This is a remarkable result that is consistent with the conclusion drawn from NMR experiments that water clusters in this material are the smallest and most confined. The 
robustness of the optical clarity of the film during water immersion is of practical relevance for applications in protective clear coatings.
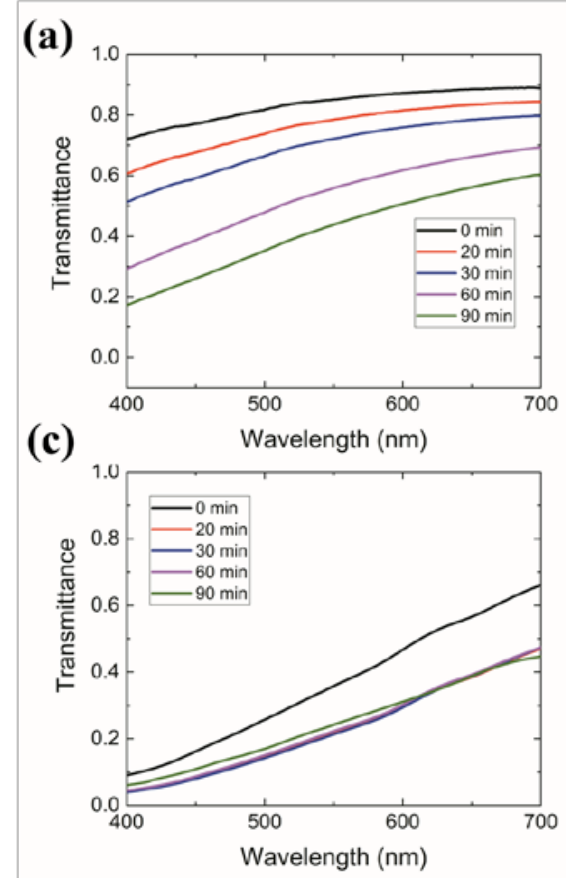

(b)

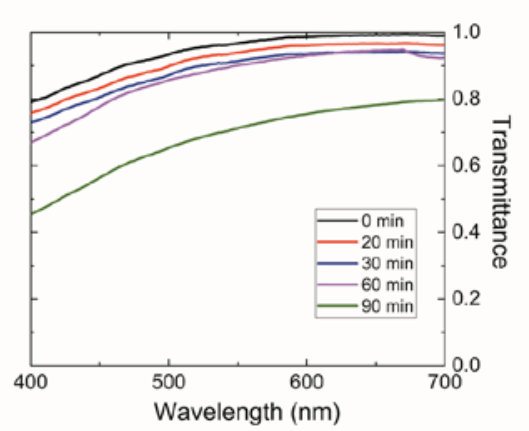

(d)
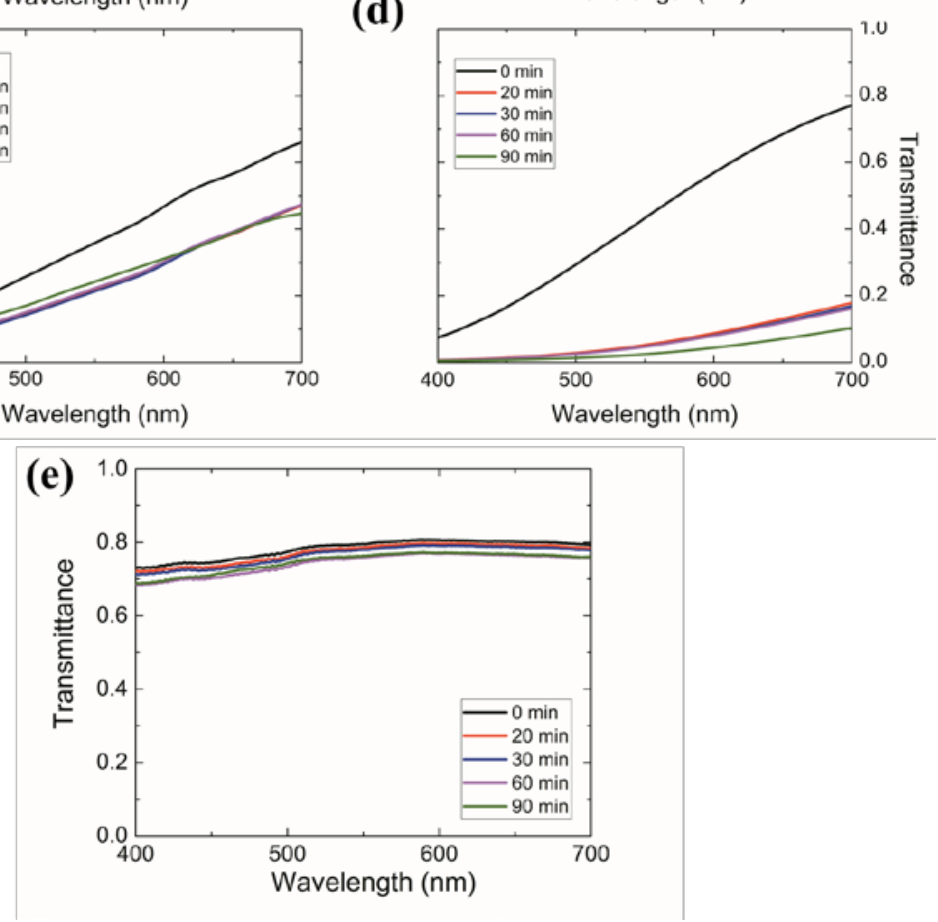

Figure 6. Transmittance as a function of wavelength for various times of immersion in water for dried films from each of the five latexes: (a) PMAA-1; (b) PMAA-1.5; (c) MAA-1; (d) MAA-1.5; and (e) PSSNa-1. 
Water vapor sorption. To gain further insights into the distribution of hydrophilic species within the films, dynamic vapor sorption experiments were carried out. Whereas liquid water uptake can continue increasing over time as water pockets grow in size, water vapor sorption measurements are made when the sample reaches thermodynamic equilibrium with the surroundings. In these experiments, the sample is placed in a chamber with controlled temperature where the water activity (RH/100), $\alpha_{w}$, is increased in steps of 0.1 and the mass is recorded as a function of time (as shown in Figure 7a). The equilibrium sorbed amount is obtained as a function of water activity to provide a sorption isotherm. The isotherms for the different materials have been plotted in Figure 7b-c. Remarkably, the films made of latex particles synthesized in the presence of macroRAFT agents sorb much less water than those synthesized by surfactant-free emulsion polymerization. The amount of macroRAFT agent or MAA influences the final equilibrium sorption, with the 1 wt\% PMAA or MAA films showing lower sorption than those materials with $1.5 \mathrm{wt} \%$. Also, the PSSNa-1 film sorbs less than 4 wt.\% at 90\% relative humidity, and which is slightly less than the PMAA-1 film (Figure 7c). The equilibrium vapor sorption of PSSNa-1 films is only slightly greater than the theoretical 3.2 wt.\% equilibrium sorption of the P(MMA-co-BA) copolymer, which shows that the PMAA chains and any residual particle interfaces have only a small effect.

Three different sorption models were used to fit the data in Figure 7b-c: the BrunauerEmmett-Teller (BET) model, ${ }^{42}$ the ENSIC model, ${ }^{43}$ and the Guggenheim-Anderson-De Boer (GAB) model. ${ }^{44}$ The GAB model can be formulated as:

$$
m_{t}=\frac{m_{m} C_{G A B} K \alpha_{w}}{\left(1-K \alpha_{w}\right)\left(1+\left(C_{G A B}-1\right) K \alpha_{w}\right)}
$$

where $m_{m}$ is the monolayer moisture content (in units of $\mathrm{g} \mathrm{H}_{2} \mathrm{O} / 100 \mathrm{~g}$ ), $K$ is the ratio of the heat of absorption to the heat of liquefaction, and $C_{\mathrm{GAB}}$ is a material constant. A comparison of the models 
determined that the GAB model provided the best fitting based on a $\chi^{2}$ correlation parameter. Graphs comparing the three models can be found in Figure S3, and the GAB fittings of the experimental data are shown in Figure 7b and c. The best-fit parameters are listed in Table 3.

Comparing values of $m_{\mathrm{m}}$ is helpful to discuss the sorptive capacity of the different materials. Films of the control latexes (MAA-1 and MAA-1.5) show higher values of $m_{\mathrm{m}}(0.48$ and 0.56 g/100 g, respectively) when compared with PMAA-1 and PSSNa-1 (0.42 and 0.31 g/100 g, respectively), with the latter being the lowest. This finding is the opposite of what would be expected from particle size effects, as a larger particle size should result in a lower internal surface area and hence a decreased mass of the water monolayer. According to models of latex film formation, the rate of particle deformation driven by the reduction of surface energy varies inversely with particle size. ${ }^{45}$ According to the analysis in the Supporting Information, the larger MAA-1 and MAA-1.5 films have larger channel volumes than in the PMAA-1 and PSSNa-1 films, which provides greater accessibility to the hydrophilic particle surfaces.

It is notable that the value of $m_{\mathrm{m}}$ for PMAA-1.5 is the highest $(0.62 \mathrm{~g} / 100 \mathrm{~g})$ of all five materials. PMAA-1.5 also shows the highest liquid water uptake (see Table 2), indicating that even a small increase of only $0.5 \mathrm{wt} \%$ in the amount of macroRAFT agent is enough to affect the water barrier properties detrimentally. The values for all five materials comparable favorably with what was found elsewhere for films from a conventional styrene-acrylate copolymer latex, which has $m_{\mathrm{m}}=$ $0.73 \mathrm{~g} / 100 \mathrm{~g}{ }^{46}$ 

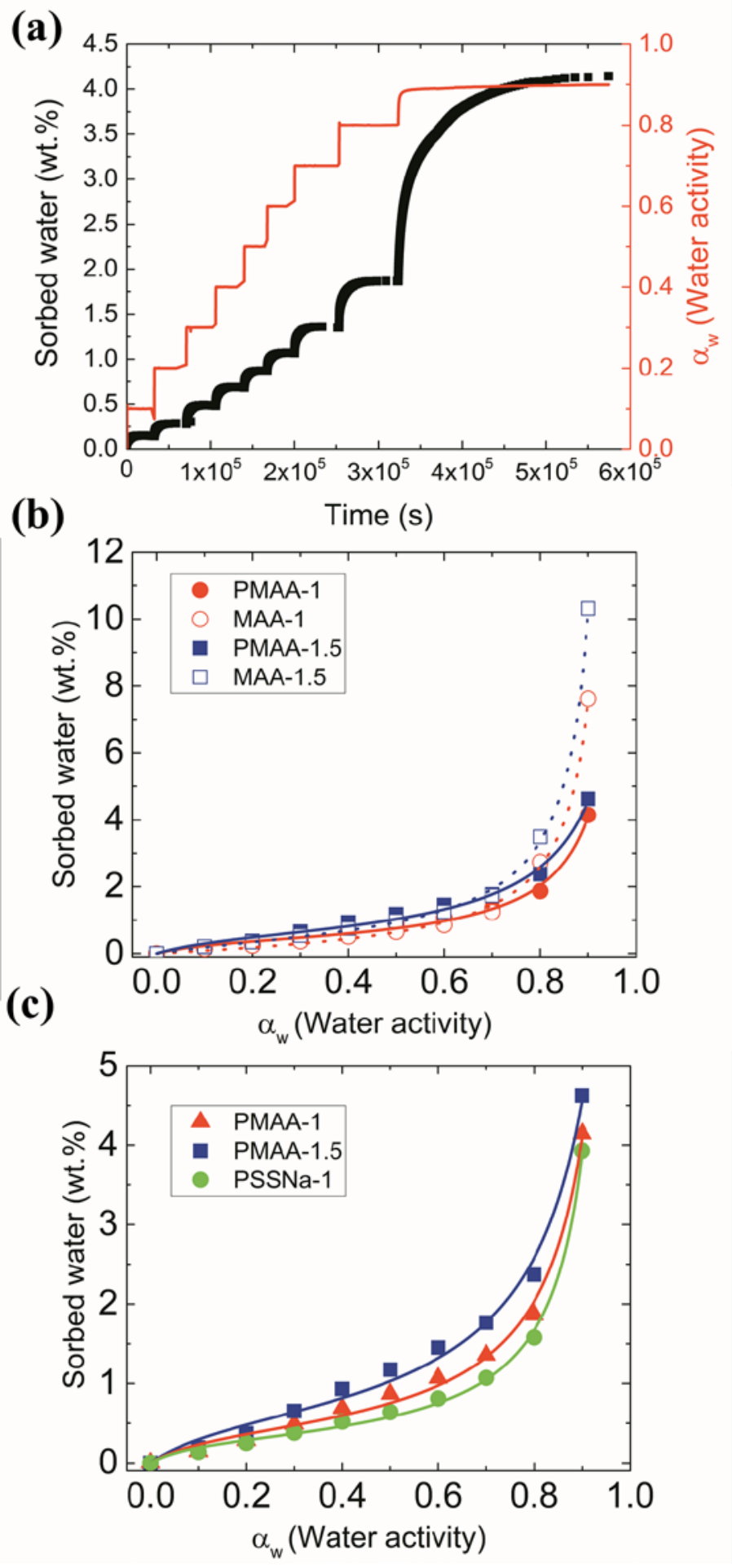

Figure 7. Water vapor sorption kinetics in a latex film made from particles synthesized using 1 wt $\%$ PMAA macroRAFT agent, as the water activity, $\alpha_{w}$, increases step-wise over a range from 0 
to 0.9 with increments of 0.1 . The black line is the water vapor uptake curve. The red line shows the corresponding steps in water activity (b) and (c): Water sorption isotherms for the different types of latex films. The data points represent the experimental data. The lines show the best fit to the GAB model using the parameters listed in Table 3.

Table 3. Fit parameters of the GAB model for water vapor sorption for the different types of latex films.

$\begin{array}{ccccc}\text { Sample } & m_{m}(\mathrm{~g} / 100 \mathrm{~g}) & C_{G A B} & K(\mathrm{~J} / \mathrm{J}) & \mathrm{R}^{2} \\ \text { PMAA-1 } & 0.42 & 8.80 & 1.00 & 0.99291 \\ \text { PMAA-1.5 } & 0.61 & 7.23 & 0.97 & 0.99076 \\ \text { MAA-1 } & 0.48 & 1.61 & 1.04 & 0.99761 \\ & & & & \\ \text { MAA-1.5 } & 0.56 & 3.47 & 1.05 & 0.99903 \\ & & & & 0.99752\end{array}$

The vapor sorption data also provide information on the kinetics of water transport through the materials. Each of the steps in the water uptake curve shown in Figure 7a can be fitted using the standard model of Fickian diffusion. If the water has a single diffusion coefficient, $D$, in the polymer, the normalized mass sorption of water is given by the equation: ${ }^{47}$

$$
\left.\frac{M_{t}}{M_{\infty}}=1-\frac{8}{\pi^{2}} \sum_{n=0}^{\infty} \frac{1}{(2 n+1)^{2}} \exp \left[-\frac{D(2 n+1)^{2} \pi^{2} t}{l^{2}}\right]\right]
$$


where $M_{t}$ is the mass of the sorbed water in the polymer at a time $t$, and which is normalized by the total mass of sorbed water in the equilibrium state, $M_{\infty} . l$ is the film thickness of the dry film. The model was found to be in good agreement with the experimental data at water activities in the studied range. As a result, it was possible to estimate the diffusion coefficient of water in the various latex films in a range of water activity from 0 to 0.9 , as shown in Figure 8a. In general, our calculated values (on the order of $10^{-7} \mathrm{~cm}^{2} \mathrm{~s}^{-1}$ ) are higher than those reported for acrylic latex films containing surfactants, whose diffusion coefficients were reported to be on the order of $10^{-8} \mathrm{~cm}^{2} \mathrm{~s}^{-}$ ${ }^{14}{ }^{46,48}$ The results indicate a weaker interaction of the films with the water and thus a higher diffusion coefficient. In line with the behavior observed when analyzing the sorption isotherms, the diffusion coefficient also presents a strong dependence on the amount of macroRAFT agent or MAA used, with the $1 \mathrm{wt} \%$ materials having a lower diffusion coefficient than those with $1.5 \mathrm{wt} \%$. At high water activity, all diffusion coefficients converge to the same value due to water clustering. Notably, the PSSNa-based film presents a very weak interaction with water, delaying the formation of clusters of water as it is sorbed by the material. 
(a)

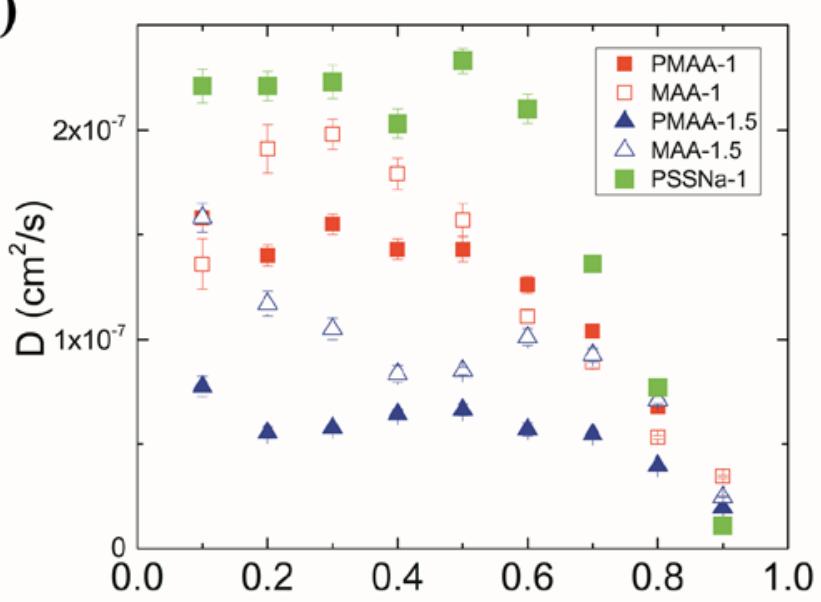

(b)

$\alpha_{w}$ (Water activity)

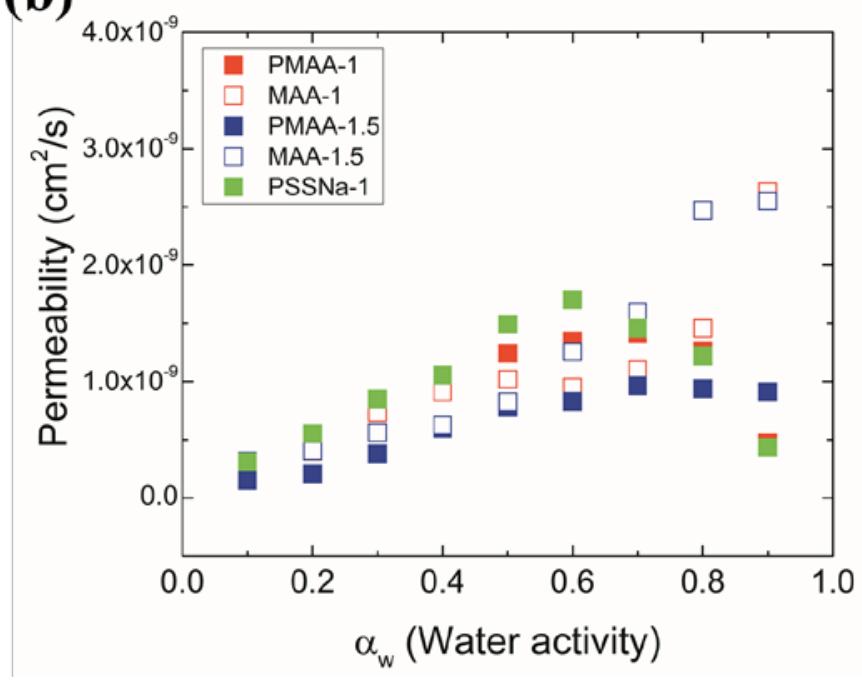

Figure 8. (a) Diffusion coefficient of water in the various polymer coatings as a function of the water activity, $\alpha_{w}$. (b) Permeability coefficient of the sorbed water vapor with an external activity of $\alpha_{\mathrm{w}}=0.9$.

In order to characterize the water transport, we calculated the permeability coefficient, $P$. For protective coatings, there is an interest in reducing the amount of water transported through a film per unit of time, which can be quantified by $P$, which is defined as the product of the solubility coefficient, $S$, and the diffusion coefficient, $D$ : 


$$
P=S \times D
$$

$S$ is obtained from the water vapor isotherms shown in Figure 7a as

$$
S=\frac{M_{\infty}-M_{0}}{M_{0}}
$$

where $M_{0}$ is the initial mass at $\mathrm{RH}=0$. Figure $8 \mathrm{~b}$ shows $P$ for water vapor in the films over a range of water activity $\alpha_{w}$ from 0 to 0.9 . At high water activities, the films formed from the macroRAFTderived latexes present lower permeabilities when compared with the surfactant-free emulsion polymer films. A lower amount of macroRAFT (1 wt\%) results in a lower permeability value at high water activities. The permeability of the macroRAFT-derived films either reaches a plateau (PMAA-1.5) or decreases after reaching a certain water activity (PMAA-1 and PSSNa-1), whereas in films obtained from the MAA latexes it keeps increasing. This trend might be related to the more robust honeycomb structure present in macroRAFT-derived films that prevents water clusters from swelling indefinitely.

According to the experiments and analyses presented here, the film cast from PSSNa-1 (containing $1 \mathrm{wt} \%$ of PSSNa) presents the best water barrier properties. It shows the lowest liquid water sorption (only $2 \mathrm{wt} \%$, see Table 2), lowest vapor sorption at 90\% RH (Table 3), and the slowest rate of water whitening (Figure 6), which makes it the most attractive material from a coating application point of view. It also shows the highest water diffusion coefficient at low water activity (Figure 8), which we interpret as a proof of a lower hydrophilicity when compared with other latexes containing a PMAA-based macroRAFT or MMA comonomer. The fact that we showed this material has the most confined sorbed water using NMR (Figure 5) explains why it 
does not show any evidence for free water in the DSC analysis (Figure 4) unlike the other macroRAFT and MAA-stabilized latexes.

The water vapor sorption experiments indicate that the polar groups are more accessible in standard emulsion latexes than in RAFT latexes. There could be several reasons for that, such as better coalescence and smaller particle size. As for differences between the two macroRAFT agents, the aromatic ring in PSSNa can provide hydrophobicity to part of the molecule, while PMAA can create strong $\mathrm{H}$ bonding with water. The reported molar water content of a carbonyl group at $\alpha_{\mathrm{w}}=0.9$ is 1.0 , whereas for a phenyl group it is $0.004 .^{49}$ The molecular weight of SSNa (206.19 $\mathrm{g} \mathrm{mol}^{-1}$ ) when compared to that of MAA (86.09 $\mathrm{g} \mathrm{mol}^{-1}$ ) means that the amount of hydrophilic groups present is smaller for a certain molecular weight. Moreover, the molecular weight for the PSSNa chains is smaller than for PMAA (see Table 1), $1210 \mathrm{~g} \mathrm{~mol}^{-1}$, which would correspond to ca. 6 SSNa units, whereas for PMAA (2290 $\mathrm{g} \mathrm{mol}^{-1}$ ) it would be $c a$. 27 MAA units. The high initial diffusion coefficients for PSSNa-1 support this idea, as it indicates a weak interaction of the water with the film.

Application as a barrier coating on steel. Our study of the water sorption of the films obtained from the surfactant-free latexes aided the selection of the best material to use in a final application. Having the most desirable barrier properties, the PSSNa-1 latex was used as the binder in a paint formulation for applications as an anti-corrosive barrier coating on steel substrates.

Several other industry-standard components were added to the formulation: a surface tension modifier to aid wetting, a flash corrosion inhibitor, a UV stabilizer, a defoamer, and butyl diglycol as a cosolvent to aid coalescence. To create a white coating, a mill base was prepared using titanium dioxide particles as the pigment, calcium carbonate as the filler, talc as an extender 
along with a phosphate corrosion inhibitor and a dispersant for the pigment. The defoamer and the surface tension modifier contain surfactant and therefore contribute hydrophilicity to the final coating. Nevertheless, they are essential components in the formulation of the paint. It is estimated from the formulation that the volatile organic compound (VOC) content is $17 \mathrm{~g} \mathrm{~L}^{-1}$, which is considered to be a very low value for a high performance barrier coating.

Coatings with a thickness of at least $75 \mu \mathrm{m}$ were deposited onto steel plates via spraying. The coatings showed good adhesion to the steel with no sign of sag, peeling or delamination. The pencil hardness was measured to be $5 \mathrm{H}$, which is suitable for applications as a barrier coating. The water contact angle on the coating was initially measured to be $71^{\circ}$, which is the same as reported in the literature for a poly(MMA-co-BA) copolymer, ${ }^{50}$ and slightly higher than $68^{\circ}$, which has been reported for poly(methyl methacrylate). ${ }^{51}$ This result indicates that the formulation of the latex did not introduce hydrophilicity to the surface.

The coatings were exposed to an accelerated weathering test to simulate outdoor exposure (following the ISO 11507:2007 standard). Alternating cycles of ultraviolet (UV) radiation and moisture at elevated temperatures were used in a commercial apparatus (QUV, Q-Lab Europe, Bolton, UK). Figure S4 shows photos of a sample during and at the end of an accelerated weathering test. A few corrosion spots formed early during the weathering test, but the coating remained intact for the remainder of the test. As a result of weathering, the gloss measurements (using a glossmeter from Sheen Instruments, UK) of the coating decreased only marginally from an initial value of 12 gloss units to a final value of 11 gloss units after $750 \mathrm{~h}$ of accelerated weathering, which indicates only a minor effect of weathering. Finally, the anticorrosion properties of the formulated paint were evaluated via a neutral salt spray (NSS) test and electrochemical impedance spectroscopy (EIS). A coated steel substrate was exposed to a saline fog mist (as per 
the ASTM B117 standard) for 96 hours. The scribed coating was adhered well with no delamination but corrosion had spread from the scribe sections, due to the absence of a surface treatment (e.g. phosphate). The EIS data clearly identified that consistent barrier performance was maintained following immersion in a dilute (0.5\%) saline solution. The low frequency region data indicated that the corrosion processes were beginning to develop but this may be addressed in future with corrosion inhibitors. We further anticipate that optimising the formulation by reducing the amount of hydrophilic additives will improve the anti-corrosion properties further. This work demonstrates that the latex synthesized with polymer stabilizers is compatible with formulation into a paint. A barrier coating on steel with promising performance was obtained.

\section{CONCLUSIONS}

Self-stabilized polymer particles in water have been synthesized making use of the polymerizationinduced self-assembly concepts, using low concentrations ( $<2 \mathrm{wt} \%)$ of PMAA or PSSNa-based macroRAFT agents. The barrier resistance to both liquid water and vapor was evaluated. Films cast from these particles were soaked in deionized water for three days, and DSC analysis was used to determine the amount of water in different states of confinement. Also, dynamic vapor sorption experiments were performed and isotherms were fit using the GAB model. Films cast from the PSSNa-1 dispersion have a lower water vapor sorption (only ca. 4 wt.\% at 90\% RH) and lower total liquid water uptake (only 4 wt.\% after three days of immersion) than found for surfactant-free latex films containing the same amount of PMAA as the stabilizer. This uptake is only slightly higher than the value predicted for the pure copolymer film, indicating that the influences of particle boundaries and hydrophilic species are minimal. The use of a lower amount of PMAA-based macroRAFT agent has a strong and positive impact on the barrier properties. NMR relaxometry of water-soaked films allowed us to determine that the water clusters have the 
smallest size in the PSSNa-1 films. The optical transmission of films immersed in water over time was measured as a means of evaluating the formation of water pockets that scatter light. The water whitening of the PSSNa-1 film is remarkably slowed down when compared to the other materials.

The fact that PSSNa-1 films remain transparent in our experiments implies good coalescence and a very small amount of defects, which matches that of some solvent-cast films. We associate this enhancement in properties with the presence of a hydrophobic aromatic ring and a reduced concentration of hydrophilic groups.

The latex stabilized with PSSNa was successfully used as the binder in a paint formulation for application as an anti-corrosive barrier coating on steel substrates. Painted panels performed well in accelerated weathering tests and moderately in neutral salt spray and electrochemical tests that evaluated the anti-corrosion properties, which points to the need for further optimisation of the formulation. Ongoing work ${ }^{23}$ is evaluating the anti-corrosion properties of crosslinking, surfactant-free binder particles using impedance spectroscopy and salt spray testing. The results presented here provide evidence for the potential of self-stabilized latex particles for the development of a range of other applications, including pressure-sensitive adhesives, ${ }^{52}$ for which water whitening is particularly detrimental when used in clear labels.

\section{SUPPORTING INFORMATION}

Description of polymer characterization methods: Nuclear magnetic resonance (NMR), size exclusion chromatography (SEC-THF), matrix assisted laser desorption ionization-time of flight mass spectrometry (MALDI-ToF MS), dynamic light scattering (DLS), pH measurements, differential scanning calorimetry (DSC). TGA and DSC thermograms for various latex films after soaking. Analysis of atomic force microscopy images: Description of procedure and geometric 
parameters. Fittings of water sorption isotherms using GAB, BET and ENSIC models. Photographs of formulated paints before and after accelerated weathering tests.

\section{AUTHOR INFORMATION}

\section{Corresponding Author}

*i.martin-fabiani@lboro.ac.uk

\section{ACKNOWLEDGMENTS}

This work was funded by the European Union Seventh Framework Programme BARRIER-PLUS project (FP7-SME-2012-2, No. 304758). We thank Sharon Hilton (Sherwin-Williams Protective \& Marine Coatings), Morgan Sibbald and Brian Skerry (The Sherwin-Willams Company) for technical advice and support. We thank Dr Marius Simina and Professor Peter J. McDonald (University of Surrey) for advice and support in the NMR analysis. We thank Violeta Doukova (University of Surrey) for general laboratory support.

\section{REFERENCES}

(1) Fulmer, P. A.; Wynne, J. H. Development of Broad-Spectrum Antimicrobial Latex Paint Surfaces Employing Active Amphiphilic Compounds. ACS Appl. Mater. Interfaces 2011, 3, 2878-2884.

(2) Price, K. K.; McCormick, A. V; Francis, L. F. CryoSEM Investigation of Latex Coatings Dried in Walled Substrates. Langmuir 2012, 28, 10329-10333.

(3) Wang, T.; Canetta, E.; Weerakkody, T. G.; Keddie, J. L.; Rivas, U. PH Dependence of the Properties of Waterborne Pressure-Sensitive Adhesives Containing Acrylic Acid. ACS Appl. Mater. Interfaces 2009, 1, 631-639.

(4) Lamminmäki, T. T.; Kettle, J. P.; Puukko, P. J. T.; Gane, P. A. C. Absorption Capability and Inkjet Ink Colorant Penetration into Binders Commonly Used in Pigmented Paper 
Coatings. Ind. Eng. Chem. Res. 2011, 50, 3287-3294.

(5) Mulqueen, P. Recent Advances in Agrochemical Formulation. Adv. Colloid Interface Sci. 2003, 106, 83-107.

(6) Gundabala, V. R.; Zimmerman, W. B.; Routh, A. F. A Model for Surfactant Distribution in Latex Coatings. Langmuir 2004, 20, 8721-8727.

(7) Baesch, S.; Siebel, D.; Schmidt-Hansberg, B.; Eichholz, C.; Gerst, M.; Scharfer, P.; Schabel, W. Comparison of Surfactant Distributions in Pressure-Sensitive Adhesive Films Dried from Dispersion under Lab-Scale and Industrial Drying Conditions. ACS Appl. Mater. Interfaces 2016, 8, 8118-8128.

(8) Gromer, A.; Thalmann, F.; Hébraud, P.; Holl, Y. Simulation of Vertical Surfactant Distributions in Drying Latex Films. Langmuir 2017, 33, 561-572.

(9) Keddie, J. L. Film Formation of Latex. Mater. Sci. Eng. R Reports 1997, 21, 101-170.

(10) Charmeau, J. Y.; Kientz, E.; Holl, Y. Adhesion of Latex Films; Influence of Surfactants. Prog. Org. Coatings 1996, 27, 87-93.

(11) Zhao, C.-L.; Holl, Y.; Pith, T.; Lambla, M. Surface Analysis and Adhesion Properties of Coalesced Latex Films. Br. Polym. J. 1989, 21, 155-160.

(12) Shirakbari, N.; Ebrahimi, M.; Salehi-Mobarakeh, H.; Khorasani, M. Effect of Surfactant Type and Concentration on Surfactant Migration, Surface Tension, and Adhesion of Latex Films. J. Macromol. Sci. Part B 2014, 53, 1286-1292.

(13) Jiang, B.; Tsavalas, J. G.; Sundberg, D. C. Water Whitening of Polymer Films: Mechanistic Studies and Comparisons between Water and Solvent Borne Films. Prog. Org. Coatings 2017, 105, 56-66.

(14) Butler, L. N.; Fellows, C. M.; Gilbert, R. G. Effect of Surfactant Systems on the Water Sensitivity of Latex Films. J. Appl. Polym. Sci. 2004, 92, 1813-1823.

(15) Lei, Y.; Child, J. R.; Tsavalas, J. G. Design and Analysis of the Homogeneous and 
Heterogeneous Distribution of Water Confined within Colloidal Polymer Particles. Colloid Polym. Sci. 2012, 291, 143-156.

(16) van Tent, A.; Tenijenhuis, K. The Film Formation of Polymer Particles in Drying Thin Films of Aqueous Acrylic Latices: II. Coalescence, Studied with Transmission Spectrophotometry. J. Colloid Interface Sci. 2000, 232, 350-363.

(17) Liu, Y.; Gajewicz, A. M.; Rodin, V.; Soer, W. J.; Scheerder, J.; Satgurunathan, G.; Mcdonald, P. J.; Keddie, J. L. Explanations for Water Whitening in Secondary Dispersion and Emulsion Polymer Films. J. Polym. Sci. Part B Polym. Phys. 2016, 1658-1674.

(18) Zoller, U.; Hushan, M. The Nonionic Surfactant Pollution Profile of Israel's Mediterranean Sea Coastal Water. Water Sci. Technol. 2001, 43, 245-250.

(19) Ping, Z. H.; Nguyen, Q. T.; Chen, S. M.; Zhou, J. Q.; Ding, Y. D. States of Water in Different Hydrophilic Polymers - DSC and FTIR Studies. Polymer (Guildf). 2001, 42, 8461-8467.

(20) Jiang, B.; Tsavalas, J.; Sundberg, D. Measuring the Glass Transition of Latex-Based Polymers in the Hydroplasticized State via Differential Scanning Calorimetry. Langmuir 2010, 26, 9408-9415.

(21) Riess, G.; Labbe, C. Block Copolymers in Emulsion and Dispersion Polymerization. Macromol. Rapid Commun. 2004, 25, 401-435.

(22) Guyot, A.; Tauer, K. Reactive Surfactants in Emulsion Polymerization BT - Polymer Synthesis; Springer Berlin Heidelberg: Berlin, Heidelberg, 1994; pp 43-65.

(23) Lesage de la Haye, J.; Martin-Fabiani, I.; Schulz, M.; Keddie, J. L.; D’Agosto, F.; Lansalot, M. Hydrophilic MacroRAFT-Mediated Emulsion Polymerization: Synthesis of Latexes for Cross-Linked and Surfactant-Free Films. Macromolecules 2017, 50, 9315-9328.

(24) Ferguson, C. J.; Hughes, R. J.; Pham, B. T. T.; Hawkett, B. S.; Gilbert, R. G.; Serelis, A. K.; Such, C. H. Effective Ab Initio Emulsion Polymerization under RAFT Control. Macromolecules 2002, 35, 9243-9245. 
(25) Chaduc, I.; Zhang, W.; Rieger, J.; Lansalot, M.; D’Agosto, F.; Charleux, B. Amphiphilic Block Copolymers from a Direct and One-Pot RAFT Synthesis in Water. Macromol. Rapid Commun. 2011, 32, 1270-1276.

(26) Blanazs, A.; Ryan, A. J.; Armes, S. P. Predictive Phase Diagrams for RAFT Aqueous Dispersion Polymerization: Effect of Block Copolymer Composition, Molecular Weight, and Copolymer Concentration. Macromolecules 2012, 45, 5099-5107.

(27) Canning, S. L.; Smith, G. N.; Armes, S. P. A Critical Appraisal of RAFT-Mediated Polymerization-Induced Self-Assembly. Macromolecules 2016, 49, 1985-2001.

(28) Lansalot, M.; Rieger, J.; D’Agosto, F. Polymerization-Induced Self-Assembly: The Contribution of Controlled Radical Polymerization to The Formation of Self-Stabilized Polymer Particles of Various Morphologies. In Macromolecular Self-assembly; John Wiley \& Sons, Inc., 2016; pp 33-82.

(29) Jennings, J.; He, G.; Howdle, S. M.; Zetterlund, P. B. Block Copolymer Synthesis by Controlled/living Radical Polymerisation in Heterogeneous Systems. Chem. Soc. Rev. 2016, 45, 5055-5084.

(30) Chenal, M.; Rieger, J.; Véchambre, C.; Chenal, J.-M.; Chazeau, L.; Creton, C.; Bouteiller, L. Soft Nanostructured Films with an Ultra-Low Volume Fraction of Percolating Hard Phase. Macromol. Rapid Commun. 2013, 34, 1524-1529.

(31) González-Matheus, K.; Leal, G. P.; Asua, J. M. Film Formation from Pickering Stabilized Waterborne Polymer Dispersions. Polymer (Guildf). 2015, 69, 73-82.

(32) Faucheu, J.; Gauthier, C.; Chazeau, L.; Cavaillé, J. Y.; Mellon, V.; Lami, E. B. Miniemulsion Polymerization for Synthesis of Structured Clay/polymer Nanocomposites: Short Review and Recent Advances. Polymer (Guildf). 2010, 51, 6-17.

(33) Agarwal, N.; Farris, R. J. Water Absorption by Acrylic-Based Latex Blend Films and Its Effect on Their Properties. J. Appl. Polym. Sci. 1998, 1407-1419.

(34) Bilgin, S.; Tomovska, R.; Asua, J. M. Effect of Ionic Monomer Concentration on Latex and 
Film Properties for Surfactant-Free High Solids Content Polymer Dispersions. Eur. Polym. J. 2017, 93, 480-494.

(35) González, E.; Paulis, M.; Barandiaran, M. J. Effect of Controlled Length Acrylic AcidBased Electrosteric Stabilizers on Latex Film Properties. Eur. Polym. J. 2014, 59, 122-128.

(36) Velasquez, E.; Rieger, J.; Stoffelbach, F.; D’Agosto, F.; Lansalot, M.; Dufils, P.-E.; Vinas, J. Surfactant-Free Poly(vinylidene Chloride) Latexes via One-Pot RAFT-Mediated Aqueous Polymerization. Polymer (Guildf). 2016, 106, 275-284.

(37) Chaduc, I.; Lansalot, M.; D’Agosto, F.; Charleux, B. RAFT Polymerization of Methacrylic Acid in Water. Macromolecules 2012, 45, 1241-1247.

(38) Song, Y.-Q.; Venkataramanan, L.; Hürlimann, M. D.; Flaum, M.; Frulla, P.; Straley, C. T1T2 Correlation Spectra Obtained Using a Fast Two-Dimensional Laplace Inversion. J. Magn. Reson. 2002, 154, 261-268.

(39) Tsavalas, J. G.; Sundberg, D. C. Hydroplasticization of Polymers: Model Predictions and Application to Emulsion Polymers. Langmuir 2010, 26, 6960-6966.

(40) Pérez, E.; Lang, J. Flattening of Latex Film Surface: Theory and Experiments by Atomic Force Microscopy. Macromolecules 1999, 32, 1626-1636.

(41) Lide, D. R. CRC Handbook of Chemistry and Physics: A Ready-Reference Book of Chemical and Physical Data; CRC Press: Boca Raton, Florida, 1992.

(42) Van Der Wel, G. K.; Adan, O. C. G. Moisture in Organic Coatings - a Review. Prog. Org. Coatings 1999, 37, 1-14.

(43) Perrin, L.; Nguyen, Q. T.; Sacco, D.; Lochon, P. Experimental Studies and Modelling of Sorption and Diffusion of Water and Alcohols in Cellulose Acetate. Polym. Int. 1997, 42, 9-16.

(44) Favre, E.; Schaetzel, P.; Nguygen, Q. T.; Clément, R.; Néel, J. Sorption, Diffusion and Vapor Permeation of Various Penetrants through Dense Poly(dimethylsiloxane) 
Membranes: A Transport Analysis. J. Memb. Sci. 1994, 92, 169-184.

(45) Dillon, R. E.; Matheson, L. A.; Bradford, E. B. Sintering of Synthetic Latex Particles. J. Colloid Sci. 1951, 6, 108-117.

(46) Liu, Y.; Soer, W.-J.; Scheerder, J.; Satgurunathan, G.; Keddie, J. L. Water Vapor Sorption and Diffusion in Secondary Dispersion Barrier Coatings: A Critical Comparison with Emulsion Polymers. ACS Appl. Mater. Interfaces 2015, 7, 12147-12157.

(47) Crank, J.; Park, G. An Evaluation of the Diffusion Coefficient for Chloroform in Polystyrene from Simple Absorption Experiments. Trans. Faraday Soc. 1949, 240-247.

(48) Kim, J.-W.; Lee, S.-M.; Hong, J.-K.; Lim, J.-C.; Kim, B.-S.; Park, S.; Hong, S. M.; Lee, H. K.; Park, J. M. Water Vapor and CO2 Permeabilities of Acrylic Latex Coatings. J. Ind. Eng. Chem. 2001, 7, 380-388.

(49) Krevelen, D. W. van; Nijenhuis, K. te. Properties Determining Mass Transfer In Polymeric Systems. In Properties of Polymers; Amsterdam, 2009; pp 655-702.

(50) Pannasri, P.; Siriphannon, P.; Monvisade, P.; Nookaew, J. Hydrothermal Growth of ZnO Nanostructures from Nano-ZnO Seeded in P(MMA-Co-BA) Matrix. J. Polym. Res. 2011, $18,2245-2254$.

(51) Ma, Y.; Cao, X.; Feng, X.; Ma, Y.; Zou, H. Fabrication of Super-Hydrophobic Film from PMMA with Intrinsic Water Contact Angle below 90. Polymer (Guildf). 2007, 48, 74557460.

(52) Aguirreurreta, Z.; Dimmer, J. A.; Willerich, I.; De La Cal, J. C.; Leiza, J. R. Water Whitening Reduction in Waterborne Pressure-Sensitive Adhesives Produced with Polymerizable Surfactants. Macromol. Mater. Eng. 2015, 300, 925-936. 
TABLE OF CONTENTS

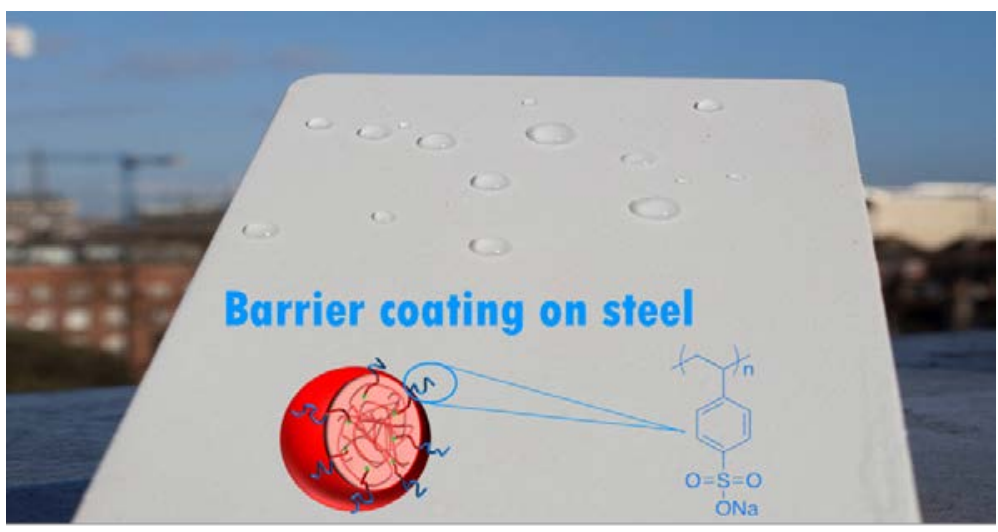

